\title{
A comparative study of simulated body fluids in the presence of proteins
}

Weitian Zhao, Jacques Lemaître and Paul Bowen

Powder Technology Laboratory, Institute of Materials, École Polytechnique Fédérale de Lausanne (EPFL), 1015 Lausanne, Switzerland

\begin{abstract}
Simulated body fluid (SBF) is widely used as part of an in vitro method to evaluate implant materials such as their apatite forming ability (AFA), a typical indication of potential bone-bonding ability in vivo. We report the use of carbonate-buffered SBFs as potential solutions for implant evaluation and the effect of proteins, represented by bovine serum albumin (BSA) in SBFs on the nucleation and growth of hydroxyapatite (HA). These solutions are buffered by the thermodynamic equilibrium with $5 \% \mathrm{CO}_{2}$ in an incubator, and result in a deposition of carbonated HA. Using several titanium-based surfaces, these solutions were studied in comparison with the widely-used SBF (ISO 23317). The presence of BSA strongly inhibited the formation of HA in traditional SBF, while HA can still be observed in carbonatebuffered SBFs. A kinetic study reveals that the inhibitory effect is concentration dependent with $0.1 \mathrm{~g} / \mathrm{L}$ and $1 \mathrm{~g} / \mathrm{L}$ of BSA having little effect on HA growth but a complete inhibition of HA formation at $5 \mathrm{~g} / \mathrm{L}$ of BSA, as tested using $\mathrm{NaOH}$ treated titanium with a known positive AFA. The decrease in solution $\mathrm{pH}$ and free calcium concentrations in SBFs due to the addition of BSA is not significant, suggesting other causes for the strong inhibitory effect.
\end{abstract}

\section{Keywords}

Bioactivity, Hydroxyapatite, SBF, Protein, Titanium

\section{Introduction}

The discovery of bone-bonding glass in the 70s by Hench et al. opened up new possibilities in bioactive implant materials, attracting many research activities and leading to the developments of various commercial products [1][2] Instead of being passively implanted and often encapsulated by fibrous tissues, these materials can actively form a direct bonding with the surrounding bone, thus significantly increasing the implant fixation and the long-term stability. The rapid development of new potential implant materials presents both scientific and technical challenges for the design of a fast assessment method other than traditional animal experiments for implant evaluation. 
Kokubo et al. proposed an in vitro method using an acellular solution with inorganic ion composition and pH similar to biological fluids called simulated body fluid (SBF) to test new implants [3][4]. The method is based on the observations that a bonelike apatite layer is often found between bioactive implants and the surrounding bone, acting as a key component for osseointegration [5]. Thus the question of material bioactivity (which hereafter refers to the bone-bonding ability), reduces to the apatite forming ability (AFA) of a material in vivo. It is further assumed that the apatite forming behavior in vivo can be reproduced using an artificial solution supersaturated with respect to hydroxyapatite (HA) in vitro, meaning that a material exhibiting HA deposition in SBF would indicate its bone-bonding ability. In 2007, the testing protocol of this in vitro method was standardized by the International Organization for Standardization (ISO 23317) and since then has been widely used as a method to evaluate various implant materials [4][6][7][8]. Despite its success, the simplifications of using a solution to mimic the body fluid and determining the bioactivity by the AFA also result in several limitations, which should be pointed out.

1. The bone bonding/formation process is essentially determined by osteoblasts, the activity of which is regulated by various local factors including both inorganic ions as well as organic growth factors.

Although hydroxyapatite is widely used as a coating on implant surfaces to increase the osteoconductivity and the in vivo formation of HA would also likely result in enhanced osseointegration [9][10], it should be noted that the osseointegration is a complex process involving platelet activation, blood clot and recruitment and migration of osteogenic cells [11]. Thus other possible mechanisms of bioactivity also exist, which could include bioactivity from specific interactions with osteoblasts/stem cells of biofunctional materials by either releasing certain biomolecules or possessing special surface topographical features [12][13]. The existence of other possible mechanisms might explain some cases of inconsistency between in vitro predictions and in vivo results [14].

2. Assuming the bone-bonding is achieved by the formation of an apatite layer, a qualitative correlation between a material's apatite forming ability in vivo and its bone-bonding strength is still difficult to establish. That is, a higher AFA in vivo does not necessarily lead to a stronger bonding. This is due to many other factors determining the final bonding strength including surface mechanical properties (adhesion between surface porous layer and bulk implant), and surface roughness, which is typically observed to be a critical factor in animal experiments [15][16].

If we limit the discussion to the chemical route (through the formation of HA) to bioactivity and focus on the in vitro method to predict in vivo AFA, there are still some issues that remain to be understood. The 
major criticism of the method is the lack of organics, especially proteins, which are abundant in human blood plasma (roughly $70 \mathrm{~g} / \mathrm{L}$ in human blood plasma [17]) and are well-known to have specific/nonspecific adsorption on various surfaces, which could affect the nucleation \& growth of apatite in SBF [18][19][20][21][22][23]. In fact, proteins, along with other organic molecules, are also active players in the regulation of the biomineralization processes in vivo [24]. Despite the existence of a number of in vitro studies on the effect of proteins, their role as promotors or inhibitors for calcium phosphate nucleation and growth is still unclear. The reported discrepancies come from varying experimental methodologies used in the literature, as well as other factors including protein concentration and conformation [25][26]. In terms of the heterogeneous nucleation/growth of HA on Ti-based implants in SBF, only a few papers can be found but no clear conclusions can be made due to the use of different SBF compositions and operating procedures [27][28].

Also, the current SBF (ISO 23317) uses tris(hydroxymethyl)aminomethane $\left(\left(\mathrm{CH}_{2} \mathrm{OH}\right)_{3} \mathrm{CNH}_{2}\right.$, Tris) to buffer the solution $\mathrm{pH}$, while Tris is not a component of human blood plasma and might have an effect on calcium phosphate nucleation [29]. The human blood is buffered by the equilibrium between carbonates and $5 \%$ partial pressure of $\mathrm{CO}_{2}$ in blood serum [30]. Due to the high structural variability of apatite crystals, the presence of carbonate species in solution will result in carbonate incorporation into the apatite lattice by either substituting the hydroxyl groups (type A) or occupying the phosphate position (type B) [31][32][33], as it is the case for apatite in natural bone [34]. Furthermore, it has also been demonstrated that carbonate complexes could lead to an increased apparent solubility of HA [35]. Despite being proposed in a review by Bohner and Lemaitre [18], unfortunately, so far there has been very limited studies using carbonate-buffered SBFs solutions for implant evaluation.

This paper aims to fill this gap and address the above-mentioned issues, namely the performance of a carbonate-buffered SBF versus the SBF proposed by Kokubo [8] and the effect of proteins on the nucleation and growth of apatite from SBF. Two new solution compositions are proposed and their ability to nucleate apatite on different representative titanium-based surfaces are compared with Kokubo's SBF, with or without the addition of protein, represented by bovine serum albumin (BSA). The effect of proteins on the kinetics of HA formation is also investigated at different protein concentrations. The changes in solution $\mathrm{pH}$ and free calcium ion concentrations in the presence of proteins are measured to help interpret the results. These studies aim to address the remaining questions in the field, the answers of which could lead to a better understanding of the system and help better interpret the results produced using SBFs. 


\section{Materials and Methods}

\subsection{Sample preparation}

Four different titanium-based surfaces were chosen for this study: i) sandpaper-polished titanium, ii) titanium - polished and heat-treated in air, iii) titanium - polished and treated with $\mathrm{NaOH}$ solution, and iv) titanium - polished, $\mathrm{NaOH}$ treated and heated in air. Commercial pure $(\mathrm{CP})$ grade 1 titanium discs (Hempel Special Metals, Switzerland) of $19 \mathrm{~mm} \times 1.5 \mathrm{~mm}$ were all machine polished before any chemical treatment. The polishing was applied on both sides of the discs using silicon carbide P320, P1200, and 1200/4000 abrasive paper consecutively, followed by washing with acetone, water and ethanol in an ultrasonic bath. The $\mathrm{NaOH}$ treatment was conducted using $5 \mathrm{M} \mathrm{NaOH}$ solution for $24 \mathrm{~h}$ at $60{ }^{\circ} \mathrm{C}$. Afterwards, the discs were washed using flowing de-ionized water for about 30s and then dried. The heat treatment was applied at $600{ }^{\circ} \mathrm{C}$ (heating rate $100{ }^{\circ} \mathrm{C} / \mathrm{h}$, natural cooling) for an hour in ambient atmosphere.

\subsection{Design and preparation of simulated body fluids}

A thermodynamic model was used to design SBFs with a target $\mathrm{pH}$ of 7.40 at testing conditions. More details about this model are given in the supplementary information (SI-1). Two new SBFs are proposed and the compositions in comparison with human blood plasma ionic concentration are given in Table 1. SBF-BCS1 was prepared by mixing equal volumes of two stock solutions A (containing $\mathrm{NaCl}, \mathrm{NaHCO}_{3}$, $\mathrm{Na}_{2} \mathrm{HPO}_{4} \cdot 2 \mathrm{H}_{2} \mathrm{O}$ and $\mathrm{Na}_{2} \mathrm{SO}_{4}$ ) and $\mathrm{B}$ (containing $\mathrm{NaCl}, \mathrm{MgCl}_{2} \cdot 6 \mathrm{H}_{2} \mathrm{O}, \mathrm{CaCl}_{2}$ and $\mathrm{HCl}$ ). SBF-BCS2 was prepared in a similar manner with additional $\mathrm{KCl}$ in solution $\mathrm{B}$ and a slightly different ionic concentration. The detailed recipe is given in the supplementary information (SI-2). The purpose of using two stock solutions is to separate calcium and phosphate ions before the AFA test to avoid undesired nucleation in a solution supersaturated with respect to several calcium phosphate phases. Both SBF-BCS1 and SBFBCS2 (hereafter abbreviated as BCS-1 and BCS-2) were designed to be used under $5 \% \mathrm{CO}_{2}$ at $36.5{ }^{\circ} \mathrm{C}$. Kokubo's corrected SBF (c-SBF) was prepared by strictly following the procedures of ISO 23317:2014 [8]. The solution was prepared using $\mathrm{NaCl}, \mathrm{NaHCO}_{3}, \mathrm{KCl}, \mathrm{K}_{2} \mathrm{HPO}_{4} \cdot 3 \mathrm{H}_{2} \mathrm{O}, \mathrm{MgCl}_{2} \cdot 6 \mathrm{H}_{2} \mathrm{O}, \mathrm{CaCl}_{2}$, and $\mathrm{Na}_{2} \mathrm{SO}_{4}$ and buffered by Tris and $\mathrm{HCl}$ solution at $36.5^{\circ} \mathrm{C}$. The final ionic concentrations are given in Table 1.

In the study of proteins in SBF, bovine serum albumin (lyophilized powder, $\geq 96 \%$, Sigma-Aldrich) was added to c-SBF, BCS-1 and BCS-2 (both in solution B) with $0.2 \mathrm{~g}$ antibacterial agent $\mathrm{NaN}_{3}$ per $1 \mathrm{~L} \mathrm{SBF}$. The $\mathrm{pH}$ values of solution BCS-1 and BCS-2 were measured using a pH meter (FiveEasy Plus, Mettler Toledo) under $5 \% \mathrm{CO}_{2}$ at $36.5{ }^{\circ} \mathrm{C}$ four times at each BSA concentration. 


\subsection{Apatite forming ability (AFA) test}

The AFA test was conducted by suspending the sample discs with an inert stainless steel wire and immersing in $50 \mathrm{~mL} \mathrm{SBF}$ in a test tube (polypropylene tubes, BD Falcon). The volume of SBF used is based on a recommended solution volume/material surface ratio $\left(\mathrm{v}_{\mathrm{s}}=100 \cdot \mathrm{S},[\mathrm{mm}]\right)$ proposed in ISO 23317 [8]. BCS-1 and BCS-2 were prepared by manually mixing the solutions A and B using a twin syringe connected with a static mixer, while c-SBF was used as prepared. All solutions were used within one day of preparation. Detailed procedures for solution preparation and AFA test procedures can be found in the operating protocols attached in the supplementary information SI-2. It should be noted in particular that due to a high carbonate concentration and a higher $\mathrm{CO}_{2}$ partial pressure in solution $\mathrm{A}$ compared to the atmosphere, it is recommended to use fresh as-prepared solutions to avoid carbonate loss during storage and handling, which could lead to an increase in solution $\mathrm{pH}$ and eventually possible undesired apatite formation when mixed with solution $\mathrm{B}$, irrespective of the presence of any testing materials. After the immersion of the samples, in the case of BCS-1 and BCS-2, the tubes were transferred into an incubator with $5 \% \mathrm{CO}_{2}$ partial pressure and a constant temperature of $36.5^{\circ} \mathrm{C}$ for the testing time before removal. Samples tested in c-SBF were put in an oven at $36.5^{\circ} \mathrm{C}$. A testing time of one week was used to compare the three solutions. In the kinetic study using BCS-2, incubation periods of 3 days, 7 days and 14 days were used. After the test, the discs were gently washed with water and ethanol and dried for surface characterization.

\subsection{Surface characterization}

X-ray diffraction (XRD) analysis was conducted using a Philips X'Pert X-ray diffractometer with $\mathrm{Cu} \mathrm{K}$

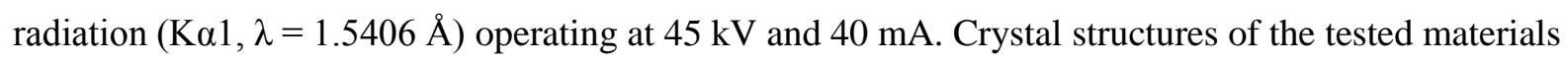
were identified using standard profiles from the JCPDS database. Surface morphologies were observed by scanning electron microscopy (SEM, Merlin (GEMINI II), Zeiss). Samples were also analyzed by Fourier transform infrared spectroscopy (FTIR, Nicolet 6700, Thermo Fisher Scientific) in attenuated total reflection (ATR) mode.

\subsection{Quantification of apatite deposition}

The amount of apatite deposited was quantified by analyzing the calcium concentrations of the remaining SBFs after the AFA test. The sample discs were taken out and 1 vol\% of $65 \mathrm{wt} \%$ concentrated $\mathrm{HNO}_{3}$ was added to the solution to prevent possible further calcium phosphate precipitation. The elemental concentrations of the solutions were analyzed by inductively coupled plasma (ICP-OES, ICPE-9800, Shimadzu). Solution B containing two times the calcium as in the final SBF was also introduced as a 
control and the amount of calcium precipitated is then calculated as the difference with the value obtained from the control group (one half of that measured concentration in solution $\mathrm{B}$ ). The dilution by $1 \%$ acid is considered in the calculation. The precipitated HA can also be semi-quantitatively analyzed by using the XRD pattern of the sample discs after immersion test by integrating the area under the apatite peak at $25.8^{\circ}$.

2.6 Measurement of free calcium concentration in the presence of BSA

The free calcium concentrations of different solutions were measured using a calcium-selective electrode (perfectION Ca Combination Electrode, Mettler Toledo), calibrated with calcium standards at $10 \mathrm{mg} / \mathrm{L}$, $100 \mathrm{mg} / \mathrm{L}$ and $1000 \mathrm{mg} / \mathrm{L}$. Calcium solutions of $20 \mathrm{~mL}$ were measured without BSA and with BSA of different concentrations at $1 \mathrm{~g} / \mathrm{L}, 5 \mathrm{~g} / \mathrm{L}, 10 \mathrm{~g} / \mathrm{L}$ and $20 \mathrm{~g} / \mathrm{L}$. The $20 \mathrm{~mL}$ solutions were prepared to have $100 \mathrm{mg} / \mathrm{L}$ of calcium by $\mathrm{CaCl}_{2}$ and were buffered with $1 \mathrm{mmol}$ Tris and $0.86 \mathrm{~mL} 1 \mathrm{M} \mathrm{HCl}$ at physiological $\mathrm{pH}$. An additional 2 vol\% ionic strength adjuster (ISA) was added to both calibration solutions and testing solutions according to the device operating protocol. Each data point was measured two times. The solution $\mathrm{pH}$ was measured three times.

\subsection{Statistical analysis}

Statistically significant differences were identified using a full factorial statistical model [36]. The model uses least squares regression methods to analyze the main effects as well as the interactions between factors adopting a type I error risk to be 5\%. Significance of regression coefficients was tested by analysis of variance (ANOVA). Linear regression is applied to two-level factors and their interactions; quadratic regression is applied to three-level factors and their interactions with other factors; cubic regression is applied to 4-levels factors and their interactions with other factors. Orthogonal polynomials are used to estimate quadratic and cubic regression coefficients.

\section{Results}

\subsection{Comparison of SBFs}

BCS-1 is based on a proposed solution JL2 by Bohner and Lemaitre in 2009 with calcium and phosphate concentrations slightly different from c-SBF [18]. BCS-2 is tuned to have the same calcium and phosphate concentration as c-SBF, thus the main difference is the higher concentration of carbonates in equilibrium with $5 \% \mathrm{CO}_{2}$ serving as a $\mathrm{pH}$ buffer. The two proposed SBFs are designed with a calculated $\mathrm{pH}$ of 7.40 at the testing condition. The $\mathrm{pH}$ measurements at these conditions give a $\mathrm{pH}$ of $7.42 \pm 0.02$ for BCS-1, and $7.41 \pm 0.01$ for BCS-2. The consistency with the calculated values validates the 
thermodynamic model used in this study (SI-1). A summary of BCS-1, BCS-2 and c-SBF is given in Table 2. The relative supersaturation $\sigma$ is calculated using the ratio of the activity product of ion units composing the crystal to the corresponding solubility product $K_{\mathrm{sp}}$ considering the number of ion units [37].

\subsection{Apatite forming ability of four Ti surfaces in different SBFs}

Four different titanium surfaces were chosen to study different SBFs with or without BSA. Chemical treatment using $\mathrm{NaOH}$ and heat treatment in air were investigated. According to the results reported in literature, an increasing order of AFA of the four surfaces is expected to be: as-polished titanium < heat treated titanium $<\mathrm{NaOH}$ and heat treated titanium $<\mathrm{NaOH}$ treated titanium [15][38][39]. The statistical design is presented in Table 3. The AFA test was conducted for 1 week.

XRD patterns of the four surfaces before AFA test reveal different crystalline phases on the surface, as shown in Figure 1 and summarized in Table 4. Heat treatment induced $\mathrm{TiO}_{2}$ rutile formation on the surface, while $\mathrm{NaOH}$ treatment led to the formation of a porous surface layer rich in $\mathrm{Ti}, \mathrm{Na}$ and $\mathrm{O}$, possibly forming a poorly crystalline $\mathrm{Na}_{0.8} \mathrm{H}_{1.2} \mathrm{Ti}_{3} \mathrm{O}_{7}$, which was further transformed by heat treatment into $\mathrm{Na}_{2} \mathrm{Ti}_{6} \mathrm{O}_{13}, \mathrm{TiO}_{2}$ rutile and possibly small amount of other sodium titanate phases. The results were similar to those reported in literature [40][41].

From the XRD patterns, it is found that after the AFA test, as-polished titanium and heat treated titanium did not have apatite on the surface in all three SBFs used, irrespective of the use of proteins. This is also confirmed in SEM, as shown in Figure S3. Nano-crystalline hydroxyapatite (01-074-0565) was identified by XRD on various surfaces as summarized in Table 4. Figure 2 gives an example of the XRD patterns of HA-covered $\mathrm{NaOH}$ treated Ti surfaces from all three SBFs without the addition of proteins. However, in the presence of $1 \mathrm{~g} / \mathrm{L} \mathrm{BSA}$, HA formation was strongly inhibited in c-SBF, while HA can still be observed in BCS-1 and BCS-2. In the case of $\mathrm{NaOH}$ and heat treated $\mathrm{Ti}$, no $\mathrm{HA}$ formation was observed in c-SBF. HA was detected with BCS-1 and BCS-2 without proteins, but only in BCS-1 in the presence of proteins. The surface morphologies are shown in Figure 3. HA was formed on $\mathrm{NaOH}$ treated Ti in all three SBFs with larger HA globules found in c-SBF. However, in the case of c-SBF, the HA layer does not fully cover the material as the exposed porous surface layer can still be occasionally observed, as can be seen in Figure 3c. It is difficult to conclude from the final morphologies the precipitation pathways, but these features seem to suggest a lower nucleation rate, which leads to fewer nucleation centers on the surface and a concurrent increase in surface area not covered by HA. In other cases, no obvious morphology differences were found between HA formed in solutions with BSA and solutions without. 
The current results suggest that $\mathrm{NaOH}$ treated Ti has a higher AFA before undergoing a further heat treatment, as expected [15]. At the same time, it also suggests that the three solutions can be ranked based on their ability to form HA on a testing material as BCS-1 > BCS-2 > c-SBF, which agrees with the calculated degrees of supersaturation with respect to HA. The presence of BSA inhibited the HA nucleation on surfaces, and no promoting effect of the BSA was observed at the current concentration of 1 $\mathrm{g} / \mathrm{L}$. It is interesting to note that in the presence of proteins, the AFA can still be expressed in the new carbonate-buffered SBFs but not in c-SBF. A general idea of the amount of HA precipitated can be obtained by calculating the area under the HA peak in the XRD patterns, shown in Figure 4. This data however only gives a semi-quantitative estimate as the peak intensity in XRD also depends on the degree of crystallinity. Nevertheless, a general consistency between XRD and SEM results can be observed.

The composition of the deposited hydroxyapatite can be compared by FTIR. Figure 5 shows a comparison of $\mathrm{NaOH}$ treated Ti immersed in BCS-1, BCS-2, c-SBF and BCS-1 with $1 \mathrm{~g} / \mathrm{L}$ BSA. HA precipitated in all these cases as detected in XRD and SEM. A broad phosphate band was found in the region from 1200 to $960 \mathrm{~cm}^{-1}$ for all the samples. The phosphate $\left(\mathrm{PO}_{4}\right)^{3-}$ also contributes to peaks at 601 and $557 \mathrm{~cm}^{-1}$. The major difference between the samples are the presence of strong bands from carbonate at 1417 and $872 \mathrm{~cm}^{-1}$ for HA precipitated from BCS-1 and BCS-2 versus c-SBF, indicating a greater incorporation of carbonate into the apatite structure. This is also expected due to the higher concentrations of carbonates in solution BCS-1 and BCS-2. In the presence of $1 \mathrm{~g} / \mathrm{L} \mathrm{BSA}, \mathrm{HA}$ still precipitated on $\mathrm{NaOH}$ treated Ti in BCS-1. At the same time, the emergence of two peaks at 1652 and $1538 \mathrm{~cm}^{-1}$ indicates the adsorption of BSA on the surface [42].

\subsection{Kinetic study of the effect of BSA at different concentrations}

A general inhibitory effect of BSA on HA nucleation was found from the results in the previous section. Further experiments were conducted to investigate the effect of protein concentrations and the growth kinetics of the apatite. $\mathrm{NaOH}$ treated Ti was tested in SBF BCS-2 at three different BSA concentrations at $0.1 \mathrm{~g} / \mathrm{L}, 1 \mathrm{~g} / \mathrm{L}$ and $5 \mathrm{~g} / \mathrm{L}$ and also in BCS-2 without BSA at three different time delays of 3 days, 7 days and 14 days using individual samples (Table 6).

XRD results indicate a positive HA deposition from solution without BSA and with BSA at $0.1 \mathrm{~g} / \mathrm{L}$ and 1 $\mathrm{g} / \mathrm{L}$ at all three time points, but a total inhibition of HA formation at $5 \mathrm{~g} / \mathrm{L}$, even after two weeks. A comparison of surfaces tested with $1 \mathrm{~g} / \mathrm{L} \mathrm{BSA}$ and $5 \mathrm{~g} / \mathrm{L} \mathrm{BSA}$ is given in Figure 6 . The results from XRD are supported by observations in SEM, shown in Figure S4. The calcium phosphate deposited from the SBF was quantified using ICP measurements of the remaining solution and is presented in Figure 7. The 
results reveal that a BSA concentration of $0.1 \mathrm{~g} / \mathrm{L}$ have little effect on the amount of $\mathrm{HA}$ growth on $\mathrm{NaOH}$ treated $\mathrm{Ti}$, whereas a BSA concentration of $1 \mathrm{~g} / \mathrm{L}$ seems to slow down the initial HA growth at 3 days but does not seem to have an effect on the HA growth afterwards. The effect of BSA becomes significant when the concentration of BSA reaches $5 \mathrm{~g} / \mathrm{L}$, where a total inhibition of HA formation takes place.

\subsection{Effect of BSA on solution $\mathrm{pH}$ and free calcium concentration}

The presence of BSA raises questions in terms of the amount of free calcium ions available in the solution, as it is known that proteins can bind $\mathrm{Ca}^{2+}$ ions [19], affecting the degree of supersaturation. The measurements of free calcium ion were conducted in calcium solutions with different BSA concentrations ranging from $0-20 \mathrm{~g} / \mathrm{L}$ in a solution buffered with Tris-HCl. The $\mathrm{pH}$ of the solution without BSA was measured to be $7.44( \pm 0.02)$. With $20 \mathrm{~g} / \mathrm{L} \mathrm{BSA}$, the $\mathrm{pH}$ measured is $7.36( \pm 0.01)$, slightly lower compared to the previous value as BSA is known to be acidic in aqueous conditions [19]. Figure 8 gives the plot of the change of available free calcium ions as a function of BSA concentration. A good linear fit can be obtained with data points collected of solutions containing BSA, showing a decrease of free $\mathrm{Ca}$ concentration with the addition of BSA. However, the first data point at $0 \mathrm{~g} / \mathrm{L} \mathrm{BSA}$ is an adjusted value using the linear extrapolation due to possible different electrode responses (raw data given in Table S3). Although a $20 \mathrm{~g} / \mathrm{L}$ BSA solution would reduce the free $\mathrm{Ca}^{2+}$ by roughly $13 \%$, a $5 \mathrm{~g} / \mathrm{L}$ BSA only reduces the free $\mathrm{Ca}^{2+}$ ions by about $3 \%$, which would decrease the relative supersaturation $\sigma_{\mathrm{HA}}$ by less than 0.3 according to calculation. This suggests that the strong inhibitory effect of proteins is unlikely a result of the decrease of available free $\mathrm{Ca}^{2+}$ ions in SBFs.

The proposed BCS-1 and BCS-2 were buffered with carbonates so the effect of BSA on solution pH was investigated separately. The $\mathrm{pH}$ values were obtained with $1 \mathrm{~g} / \mathrm{L}$ and $5 \mathrm{~g} / \mathrm{L} \mathrm{BSA}$ in two solutions under testing conditions $\left(36.5^{\circ} \mathrm{C}, \mathrm{p}\left(\mathrm{CO}_{2}\right)=5 \%\right)$, and compared with the solution $\mathrm{pH}$ without the presence of proteins (Figure 9). For both solutions, a slight decreasing trend of $\mathrm{pH}$ with BSA concentration can be observed, but the $\mathrm{pH}$ values remain close with lowest $\mathrm{pH}$ being around 7.36. Thermodynamic calculations indicate only a slight change in the relative supersaturation of HA, from 15.23 to 14.60 for BCS-1 and from 14.15 to 13.55 for BCS-2. These results indicate that the inhibitory effect of BSA on HA nucleation is also unlikely to be due to the change in solution $\mathrm{pH}$.

\section{Discussion}

Requirements of solutions as simulated body fluids 
The ability to trigger the formation of apatite from an SBF is used to imply the bioactivity of an implant in vivo. To be used as an SBF, the proposed solution should meet several requirements. i) The solution should have a $\mathrm{pH}$ value close to the physiological $\mathrm{pH}$ at around 7.40 and possess reasonable buffering capacity to maintain its $\mathrm{pH}$. The proposed BCS-1 and BCS-2 were designed to have a target $\mathrm{pH}$ of 7.40 under conditions in AFA test, which was verified experimentally. The $\mathrm{pH}$ is buffered with carbonates in equilibrium with a controlled $5 \% \mathrm{CO}_{2}$ environment in an incubator. The $\mathrm{pH}$ buffering capacity can also be calculated theoretically and is slightly better than c-SBF, shown in Figure S7. ii) The solution should not precipitate HA in the absence of the testing materials. Since SBF is supersaturated with respect to HA, theoretically no SBF will be stable indefinitely. However, it is necessary to be stable at least during the recommended testing time to avoid homogenous nucleation of $\mathrm{HA}$ in the solution, which could lead to false positive results. The stability of the solution BCS-1 and BCS-2 was investigated and confirmed for a period of 4 weeks. Details about the methodology and the results are presented in the supplementary information (SI-8). iii) The solution should deliver expected results on both negative and positive controls, namely not to have HA nucleation on materials that have been proven to be inert in vivo but to deposit HA on materials with in vivo bioactivity. Previous animal experiments have confirmed that aspolished Ti being an inert material while $\mathrm{NaOH}$ treatment could induce bioactivity of $\mathrm{Ti}$ [16][38]. The results of the present work also show that the two proposed SBFs do not show HA deposition on aspolished $\mathrm{Ti}$ but instead on $\mathrm{NaOH}$ treated $\mathrm{Ti}$, satisfying this requirement.

\section{Comparison of SBFs and the role of carbonates}

The major difference between the proposed SBF and the c-SBF is the carbonate concentration. Higher amount of carbonates can be used to buffer solution $\mathrm{pH}$ under equilibrium with $5 \% \mathrm{CO}_{2}$ but also leads to potential storage issues. In ambient conditions with $0.04 \% \mathrm{CO}_{2}$ in air, the carbonated solution could easily lose $\mathrm{CO}_{2}$ and result in a $\mathrm{pH}$ value higher than 7.40, eventually leading to a homogenous nucleation of $\mathrm{HA}$ in solution (instability). Our effort in preventing undesired homogenous nucleation was to separate the calcium and phosphate components into two stock solutions and mix them uniformly before the AFA test. Still, care should be taken with solution A due to the same reason. For the use of c-SBF, the effect of carbonates is however overlooked in the ISO protocols. The current lower carbonate concentration (4.2 $\mathrm{mM} \mathrm{HCO}_{3}^{-}$) in c-SBF is a result of instability of SBFs with higher carbonate content which leads to calcite formation [43]. In fact, even in the current concentration at $4.2 \mathrm{mM}$, the calculated partial pressure of $\mathrm{CO}_{2}$ in c-SBF is still much higher than that in air (1.0\% vs. $\left.0.04 \%\right)$, meaning it will gradually release $\mathrm{CO}_{2}$ from the solution and result in a higher $\mathrm{pH}$ value. In the current study, $1 \mathrm{~mL} 1 \mathrm{M} \mathrm{HCl}$ (for $1 \mathrm{~L}$ of $\mathrm{SBF}$ ) was added to balance the solution $\mathrm{pH}$ (Step 6 in ISO protocol). A calculation shows that depending on the degree of $\mathrm{CO}_{2}$ exchange with air, the $\mathrm{pH}$ can vary from $7.34-7.51$. This is likely the reason why a 
range (from 0 to $5 \mathrm{~mL}$ ) of $1 \mathrm{M} \mathrm{HCl}$ is given in the ISO protocol to adjust the final $\mathrm{pH}$ value to 7.40 . The issue of carbonate loss and slight change of $\mathrm{pH}$ during preparation and storage of the c-SBF is in general not taken into account. Although at the time of preparation the solution $\mathrm{pH}$ is adjusted to 7.40 , during the storage and the use, the slight carbonate loss would still increase the $\mathrm{pH}$ and thus the supersaturation of the solution, which could potentially lead to inconsistent results from following this protocol. A detailed analysis is given in SI-9. A fixed volume of additional $\mathrm{HCl}$ and the awareness of possible carbonate exchange is recommended for the use of c-SBF.

Possible causes of the inhibitory effect of BSA

In this study, the inhibitory effect of BSA on the nucleation of HA has been observed in all three SBFs used. As the possible complexation effect with free $\mathrm{Ca}^{2+}$ ions was previously reported [44], we investigated the decrease of free $\mathrm{Ca}^{2+}$ ions by proteins using a calcium-selective electrode. A small decrease in free calcium ions ( $3 \%$ at $5 \mathrm{~g} / \mathrm{L} \mathrm{BSA})$ was found, which by itself can hardly explain a complete inhibition of HA formation. The effect of $\mathrm{pH}$ change has also been confirmed to have a negligible effect on supersaturation and hence HA nucleation and growth. On the other hand, protein adsorption on surfaces is a common phenomenon. The adsorption of proteins onto implant surfaces would serve as a competitive event for adsorption of inorganic species such as $\mathrm{Ca}^{2+}, \mathrm{PO}_{4}{ }^{3-}$ or $\mathrm{HPO}_{4}{ }^{2-}$, thus affecting the nucleation of calcium phosphates. Recently, non-classical nucleation theory has been proposed for several calcium systems and pre-nucleation clusters in the system of Ca-P has been observed [45][46][47]. Although the active nucleation species in the SBF under discussion here remain unknown, proteins might have a stabilization effect on the pre-nucleation clusters, thus affecting the nucleation event. Currently, efforts are also being made to approach the problem from a fundamental perspective using atomistic simulations, such as the competitive adsorption of organic materials with inorganic ions onto model surfaces such as rutile.

Possible improvement of the current AFA protocol

Potential ways to improve the use of SBFs in implant evaluation can be suggested from our study. Essentially, the formation of HA from SBF is a heterogeneous nucleation process. Different materials have different abilities to trigger HA deposition in vivo or in vitro. At the same time, different SBFs also have different tendencies to deposit HA on the same material. Assuming the HA layer formed in vivo has a promoting effect on bone growth and bonding, then the question is to find an SBF with the right degree of supersaturation with respect to HA to distinguish materials able to trigger HA deposition in vivo from materials which cannot. A simple mimic of blood plasma based on total ion concentrations however cannot guarantee complete successful predictions, considering the obvious differences between the 
implantation environments in human bone defects versus a solution with solely inorganic ions. However, tuning of the supersaturation levels of the solution can get us closer to better predictions. At the same time, the experimental details including the handling of SBFs (control of carbonate loss), the renewal of solution in long-term studies, or the presence of confined space in SBF, all could have an equally important role in determining the final outcome [39]. Standardization of the operating procedures with a finer control of experimental details is needed to reduce the number of conflicting results in the field generated using different SBF compositions and different experimental conditions. Understanding the complexity and the subtleties of the system is crucial in understanding and interpreting the results produced using SBFs.

With the knowledge of the inhibitory effect of BSA on HA nucleation, it is recommended to consider adding proteins into the SBF, not because it would decrease the ability to form HA, which could be compensated by adding more inorganic ions, but because of its possible specific interactions with certain materials especially porous materials, thus having different inhibitory behaviors on different materials. In the current study, it seems that in the presence of proteins, carbonate-buffered SBFs, compared to c-SBF, can still generate results that corresponds to the conclusions from in vivo experiments, where proteins are in abundance.

Despite limitations of the in vitro SBF method, and the emergence of new functional materials with specific cell interactions, which no longer rely on calcium phosphate formation to achieve bioactivity, the authors still consider the method of using SBFs as an in vitro method to be a significant contribution to the field of implant research, serving as a first screening step for potential implants, especially Ti-based materials. Possible improvements of the current method would be beneficial.

\section{Conclusions and outlook}

The current study compared commonly used c-SBF with carbonate-buffered BCS-1 and BCS-2 containing higher concentration of carbonates. All the solutions were able to distinguish bioactive $\mathrm{NaOH}-$ treated Ti and inert as-polished Ti in the AFA test. The presence of BSA in SBF has an inhibitory effect on the nucleation of HA on bioactive surfaces. In the case of $\mathrm{NaOH}$ treated $\mathrm{Ti}$, no HA can be observed with $1 \mathrm{~g} / \mathrm{L}$ BSA in Kokubo's c-SBF with a Tris-HCl buffer. However, HA can still be detected in the new carbonate-buffered BCS-1 and BCS-2. For $\mathrm{NaOH}$ and heat treated Ti, no HA was found with c-SBF irrespective of the addition of BSA but can be found when using BCS-1 and BCS-2 without BSA. Further addition of BSA exhibited a strong inhibitory effect with only BCS-1 being able to produce HA, 
indicating a higher ability to precipitate $\mathrm{HA}$ in the presence of proteins. Using $\mathrm{NaOH}$ treated $\mathrm{Ti}$, the effect of BSA was further confirmed to be concentration dependent with minor effect at $0.1 \mathrm{~g} / \mathrm{L}$ and $1 \mathrm{~g} / \mathrm{L}$ but a full inhibition when the concentration reached $5 \mathrm{~g} / \mathrm{L}$. The measurements of solution $\mathrm{pH}$ and free calcium concentration changes due to BSA suggest that the inhibitory effect is not likely to be a result of the decrease of $\mathrm{pH}$ or free calcium ions in SBFs.

Proteins were found to have a profound effect on HA nucleation at a concentration much lower than that in human blood plasma. Consequently, the inclusion of proteins in SBFs should receive more attention in future research. Particularly, it would be interesting to identify proteins in human blood plasma that are the key players in controlling the HA nucleation. The complexity of the system calls for the use of statistical design of experiments to identify key parameters and their possible interplay. In the end, the ability for accurate prediction of in vivo results of any proposed SBF should be validated by animal experiments. This is currently under investigation and will be reported in the near future.

\section{Acknowledgements}

The authors would like to thank Swiss National Science Foundation (Project 205321 - 150193) for providing financial support for this work.

\section{References}

[1] W.C.A. and T.K.G. L. L. Hench, R. J. Splinter, Bonding mechanisms at the interface of ceramic prosthetic materials, J. Biomed. Mater. Res. 5 (1971) 117-141.

[2] J.R. Jones, Review of bioactive glass: From Hench to hybrids, Acta Biomater. 9 (2013) 44574486.

[3] T. Kokubo, H. Kushitani, S. Sakka, T. Kitsugi, T. Yamamum, Solutions able to reproduce in vivo surface-structure changes in bioactive glass-ceramic A-W, J. Biomed. Mater. Res. 24 (1990) 721734.

[4] T. Kokubo, H. Takadama, How useful is SBF in predicting in vivo bone bioactivity?, Biomaterials. 27 (2006) 2907-2915.

[5] T. Kokubo, Surface chemistry of bioactive glass-ceramics, J. Non. Cryst. Solids. 120 (1990) 138151.

[6] T. Kokubo, H.M. Kim, M. Kawashita, T. Nakamura, Bioactive metals: Preparation and properties, J. Mater. Sci. Mater. Med. 15 (2004) 99-107. 
[7] T. Kokubo, S. Yamaguchi, Novel bioactive titanate layers formed on Ti metal and its alloys by chemical treatments, Materials. 3 (2010) 48-63.

[8] T. Kokubo, Implants for surgery - In vitro evaluation for apatite-forming ability of implant materials, ISO 23317:2014, 2014.

[9] S.D. Cook, K.A. Thomas, J.F. Kay, M. Jarcho, Hydroxyapatite-coated porous titanium for use as an orthopedic biologic attachment system., Clin. Orthop. Relat. Res. 230 (1988) 303-12.

[10] S. Nishiguchi, S. Fujibayashi, H.-M. Kim, T. Kokubo, T. Nakamura, Biology of alkali- and heattreated titanium implants., J. Biomed. Mater. Res. A. 67 (2003) 26-35.

[11] J. Davies, Understanding peri-implant endosseous healing, J. Dent. Educ. 67 (2003) 932-949.

[12] P. Tambasco De Oliveira, A. Nanci, Nanotexturing of titanium-based surfaces upregulates expression of bone sialoprotein and osteopontin by cultured osteogenic cells, Biomaterials. 25 (2004) 403-413.

[13] T. Kaito, A. Myoui, K. Takaoka, N. Saito, M. Nishikawa, N. Tamai, H. Ohgushi, H. Yoshikawa, Potentiation of the activity of bone morphogenetic protein- 2 in bone regeneration by a PLAPEG/hydroxyapatite composite, Biomaterials. 26 (2005) 73-79.

[14] A.A. Zadpoor, Relationship between in vitro apatite-forming ability measured using simulated body fluid and in vivo bioactivity of biomaterials, Mater. Sci. Eng. C. 35 (2014) 134-143.

[15] H.M. Kim, F. Miyaji, T. Kokubo, T. Nakamura, Effect of heat treatment on apatite-forming ability of Ti metal induced by alkali treatment, J. Mater. Sci. Mater. Med. 8 (1997) 341-347.

[16] S. Nishiguchi, T. Nakamura, M. Kobayashi, H.M. Kim, F. Miyaji, T. Kokubo, The effect of heat treatment on bone-bonding ability of alkali-treated titanium, Biomaterials. 20 (1999) 491-500.

[17] L. Sava, S. Pillai, U. More, A. Sontakke, Serum calcium measurement: Total versus free (ionized) calcium., Indian J. Clin. Biochem. 20 (2005) 158-161.

[18] M. Bohner, J. Lemaitre, Can bioactivity be tested in vitro with SBF solution?, Biomaterials. 30 (2009) 2175-9.

[19] J.E. Ellingsen, A study on the mechanism of protein adsorption to $\mathrm{TiO}_{2}$, Biomaterials. 12 (1991) 593-596.

[20] V. Hlady, H. Füredi-Milhofer, Adsorption of human serum albumin on precipitated hydroxyapatite, J. Colloid Interface Sci. 69 (1979) 460-468.

[21] J. Garnett, P. Dieppe, The effects of serum and human albumin on calcium hydroxyapatite crystal growth., Biochem. J. 266 (1990) 863-868.

[22] D.T.H.W.G. Embery, Adsorption of bovine serum albumin on to titanium powder, Biomaterials. 17 (1996) 859-864.

[23] V. Vergaro, C. Carlucci, M. Cascione, C. Lorusso, F. Conciauro, B.F. Scremin, P.M. Congedo, G. 
Cannazza, C. Citti, G. Ciccarella, Interaction between Human Serum Albumin and Different Anatase $\mathrm{TiO}_{2}$ Nanoparticles : A Nano-bio Interface Study Regular Paper, Nanomater. Nanotechnol. 5 (2015) 1-12.

[24] S. Mann, D.D. Archibald, J.M. Didymus, T. Douglas, B.R. Heywood, F.C. Meldrum, N.J. Reeves, Crystallization at Inorganic-Organic Interfaces: Biominerals and Biomimetic Synthesis, Science 261 (1993) 1286-1292.

[25] H. Pan, X. Zhao, B.W. Darvell, W.W. Lu, Apatite-formation ability - Predictor of "bioactivity"?, Acta Biomater. 6 (2010) 4181-4188.

[26] A. Lussi, M.A. Crenshaw, A. Linde, Induction and inhibition of hydroxyapatite formation by rat dentine phosphoprotein in vitro, Arch. Oral Biol. 33 (1988) 685-691.

[27] V. Stenport, P. Kjellin, M. Andersson, F. Currie, Y.-T. Sul, a Wennerberg, a Arvidsson, Precipitation of calcium phosphate in the presence of albumin on titanium implants with four different possibly bioactive surface preparations. An in vitro study., J. Mater. Sci. Mater. Med. 19 (2008) 3497-505.

[28] A. Arvidsson, F. Currie, P. Kjellin, Y.-T. Sul, V. Stenport, Nucleation and growth of calcium phosphates in the presence of fibrinogen on titanium implants with four potentially bioactive surface preparations. An in vitro study., J. Mater. Sci. Mater. Med. 20 (2009) 1869-79.

[29] M.T. Jahromi, G. Yao, M. Cerruti, The importance of amino acid interactions in the crystallization of hydroxyapatite., J. R. Soc. Interface. 10 (2013) 20120906.

[30] J.. L.. Gamble, J. Lawder, Chemical anatomy, physiology and pathology of extracellular fluid : a lecture syllabus, Harvard Medical School, 1941.

[31] L. Muller, F.A. Muller, Preparation of SBF with different $\mathrm{HCO}_{3}{ }^{-}$content and its influence on the composition of biomimetic apatites, Acta Biomater. 2 (2006) 181-189.

[32] Q.J. He, Z.L. Huang, X.K. Cheng, J. Yu, Thermal stability of porous A-type carbonated hydroxyapatite spheres, Mater. Lett. 62 (2008) 539-542.

[33] E. Landi, G. Celotti, G. Logroscino, a. Tampieri, Carbonated hydroxyapatite as bone substitute, J. Eur. Ceram. Soc. 23 (2003) 2931-2937.

[34] C. Rey, B. Collins, T. Goehl, I.R. Dickson, M.J. Glimcher, The carbonate environment in bone mineral: A resolution-enhanced fourier transform infrared spectroscopy study, Calcif. Tissue Int. 45 (1989) 157-164.

[35] H. Pan, B.W. Darvell, Effect of carbonate on hydroxyapatite Solubility, Cryst. Growth Des. 10 (2010) 845-850.

[36] D.C. Montgomery, Design and Analysis of Experiments, 5th Edition, Wiley, 2000.

[37] W. Wu, G.H. Nancollas, Kinetics of heterogeneous nucleation of calcium phosphates on anatase 
and rutile surfaces, J. Colloid Interface Sci. 199 (1998) 206-211.

[38] S. Nishiguchi, H. Kato, H. Fujita, M. Oka, H.M. Kim, T. Kokubo, T. Nakamura, Titanium metals form direct bonding to bone after alkali and heat treatments, Biomaterials. 22 (2001) 2525-2533.

[39] X.-X. Wang, W. Yan, S. Hayakawa, K. Tsuru, A. Osaka, Apatite deposition on thermally and anodically oxidized titanium surfaces in a simulated body fluid, Biomaterials. 24 (2003) 46314637.

[40] S. Yamaguchi, H. Takadama, T. Matsushita, T. Nakamura, T. Kokubo, Cross-sectional analysis of the surface ceramic layer developed on Ti metal by $\mathrm{NaOH}$-heat treatment and soaking in SBF, J. Ceram. Soc. Japan. 117 (2009) 1126-1130.

[41] T. Kokubo, S. Yamaguchi, Bioactive Ti metal and its alloys prepared by chemical treatments: State-of-the-art and future trends, Adv. Eng. Mater. 12 (2010) 579-591.

[42] J. Grdadolnik, Y. Maréchal, Bovine serum albumin observed by infrared spectrometry. I. Methodology, structural investigation, and water uptake., Biopolymers. 62 (2001) 40-53.

[43] A. Oyane, H.-M. Kim, T. Furuya, T. Kokubo, T. Miyazaki, T. Nakamura, Preparation and assessment of revised simulated body fluids., J. Biomed. Mater. Res. A. 65 (2003) 188-195.

[44] J. Lima, S.R. Sousa, A. Ferreira, M.A. Barbosa, Interactions between calcium phosphate and albumin on the surface of titanium, J. Biomed. Mater. Res. 55 (2000) 45-53.

[45] J.J. De Yoreo, P.U.P.A. Gilbert, N.A.J.M. Sommerdijk, R.L. Penn, S. Whitelam, D. Joester, H. Zhang, J.D. Rimer, A. Navrotsky, J.F. Banfield, A.F. Wallace, F.M. Michel, F.C. Meldrum, H. Colfen, P.M. Dove, Crystallization by particle attachment in synthetic, biogenic, and geologic environments, Science 349 (2015) aaa6760.

[46] A.K. Bertram, T. Koop, L.T. Molina, M.J. Molina, Clustering of Calcium Phosphate in the System $\mathrm{CaCl}_{2}-\mathrm{H}_{3} \mathrm{PO}_{4}-\mathrm{KCl}-\mathrm{H}_{2} \mathrm{O}$, J. Phys. Chem. B. Phys. Chem. B. 103 (1999) 8230-8235.

[47] W.J.E.M. Habraken, J. Tao, L.J. Brylka, H. Friedrich, L. Bertinetti, A.S. Schenk, A. Verch, V. Dmitrovic, P.H.H. Bomans, P.M. Frederik, J. Laven, P. van der Schoot, B. Aichmayer, G. de With, J.J. DeYoreo, N.A.J.M. Sommerdijk, Ion-association complexes unite classical and non-classical theories for the biomimetic nucleation of calcium phosphate, Nat. Commun. 4 (2013) 1507. 


\section{Figure legends:}

Figure 1. XRD patterns of four surfaces before immersion in SBF. Pure Ti is identified for as-polished titanium. For $\mathrm{NaOH}$ treated Ti, poorly crystalline sodium hydrogen titanate (SHT) $\mathrm{Na}_{0.8} \mathrm{H}_{1.2} \mathrm{Ti}_{3} \mathrm{O}_{7}(00-$ 048-0693) can be identified in addition to $\mathrm{Ti}$. Ti and rutile (R) $\mathrm{TiO}_{2}(01-089-4920)$ are found on heat treated Ti. $\mathrm{NaOH}$ and heat treatment results in a mixture of $\mathrm{Ti}, \mathrm{TiO}_{2}$ rutile (01-089-4920), and sodium titanate (ST) $\mathrm{Na}_{2} \mathrm{Ti}_{6} \mathrm{O}_{13}(00-037-0951)$. It is possible that $\mathrm{Ti}_{6} \mathrm{O}(01-072-1807)$ is also formed on the surface after heat treatments due to the split of the Ti peak at $37^{\circ}$.

Figure 2. XRD patterns of $\mathrm{NaOH}$ treated Ti surfaces after immersion in BCS-1, BCS-2 and c-SBF for one week. Sodium hydrogen titanate (SHT) and titanium (Ti) peaks are indicated and HA peaks are marked with a triangle. In the calcium phosphate family, OCP and HA have similar diffraction patterns at $20^{\circ}-45^{\circ}$ but the absence of peaks at around $5^{\circ}$ confirmed the formation of HA instead of OCP.

Figure 3. SEM images of surfaces immersed in various SBFs for one week. Three columns from left to right are with BCS-1 (a, d, g, j), BCS-2 (b, e, h, k) and c-SBF (c, f, i, l), respectively. Two top rows are with $\mathrm{NaOH}$ treated $\mathrm{Ti}(\mathrm{a}, \mathrm{b}, \mathrm{c}), \mathrm{NaOH}$ and heat treated $\mathrm{Ti}(\mathrm{d}, \mathrm{e}, \mathrm{f})$ without BSA in SBF. Bottom two rows are the same $\mathrm{NaOH}$ treated $\mathrm{Ti}(\mathrm{g}, \mathrm{h}, \mathrm{i}), \mathrm{NaOH}$ and heat treated $\mathrm{Ti}(\mathrm{j}, \mathrm{k}, \mathrm{l})$ with $1 \mathrm{~g} / \mathrm{L}$ BSA in solution. Apatite formation can be easily identified by the presence of globules consisting of tiny flake-like crystals, the characteristic morphologies of HA deposited from SBF. The presence of porous surface in the case of $\mathrm{f}, \mathrm{i}, \mathrm{k}$ and 1 indicates no HA deposition. All scale bars are $2 \mu \mathrm{m}$.

Figure 4. Amounts of HA deposition on various surfaces in different SBFs calculated by area integration under the XRD peak of HA at $25.8^{\circ}$. The error bars correspond to $95 \%$ confidence intervals. Both two replicates were analyzed.

Figure 5. FTIR transmission spectra of $\mathrm{NaOH}$ treated Ti after AFA test in different SBFs.

Figure 6. XRD patterns of $\mathrm{NaOH}$ treated Ti in BCS-2 with $1 \mathrm{~g} / \mathrm{L}$ and $5 \mathrm{~g} / \mathrm{L}$ BSA at three different time delays. The titanium (Ti) and sodium hydrogen titanate (SHT) are marked and the HA peaks are labeled with triangles. 
Figure 7. Quantitative kinetic study of HA growth on $\mathrm{NaOH}$ treated $\mathrm{Ti}$ in $\mathrm{BCS}-2$ with different protein concentrations. The graph is based on the fitted values using statistical analysis on the original data adopting a type I error risk of 5\%. The plot of raw data is given in supplementary information Figure S5.

Figure 8. Plot of free calcium ion concentration with different BSA concentrations. Data were normalized to the free calcium in solution without BSA. A linear fit of the data obtained with the presence of BSA gives: $\mathrm{y}=1.000-0.007 \cdot \mathrm{x}, \mathrm{R}^{2}=0.996$.

Figure 9. $\mathrm{pH}$ values measured of BCS-1 and BCS-2 without BSA and in the presence of BSA at $1 \mathrm{~g} / \mathrm{L}$ and $5 \mathrm{~g} / \mathrm{L}$. The column chart is based on the fitted values using statistical analysis on the original data adopting a type I error risk of 5\%. Only the factor of protein concentration was shown to be significant ( $p$ $<0.001)$. The plot of raw data is given in supplementary information Figure S6. 


\section{Tables:}

Table 1. Compositions of SBFs and human blood plasma.

\begin{tabular}{lrrrrr}
\hline \multicolumn{5}{c}{ Concentration [mM] } \\
\cline { 2 - 6 } Ion & $\begin{array}{r}\text { Human Blood Plasma [30] } \\
\text { Total }\end{array}$ & Dissociated & c-SBF & BCS-1 & BCS-2 \\
\hline $\mathrm{Na}^{+}$ & 142.0 & 142.0 & 142.0 & 143.0 & 142.0 \\
$\mathrm{~K}^{+}$ & 5.0 & 5.0 & 5.0 & -- & 5.0 \\
$\mathrm{Mg}^{2+}$ & 1.5 & 1.0 & 1.5 & 1.5 & 1.5 \\
$\mathrm{Ca}^{2+}$ & 2.5 & 1.3 & 2.5 & 2.3 & 2.5 \\
$\mathrm{Cl}^{-}$ & 103.0 & 103.0 & $147.8^{a}$ & $124.6^{a}$ & $129.4^{a}$ \\
$\mathrm{HCO}_{3}{ }^{-}$ & 27.0 & 27.0 & 4.2 & 22.2 & 22.6 \\
$\mathrm{HPO}_{4}{ }^{2-}$ & 1.0 & 1.0 & 1.0 & 1.4 & 1.0 \\
$\mathrm{SO}_{4}{ }^{2-}$ & 0.5 & 0.5 & 0.5 & 0.5 & 0.5 \\
\hline $\mathrm{Additional}$ & & & & & \\
$\mathrm{TRIS}^{-}$ & -- & -- & 50.0 & -- & -- \\
$\mathrm{HCl}$ & -- & -- & 40.0 & 1.0 & 1.2 \\
\hline
\end{tabular}

${ }^{a}$ The chloride ion concentration does not include added $\mathrm{HCl}$ solution as $\mathrm{pH}$ buffer.

Table 2. A comparison of different SBFs used. The relative supersaturation values of different minerals are calculated. Hydroxyapatite (HA): $\mathrm{Ca}_{5}\left(\mathrm{PO}_{4}\right)_{3}(\mathrm{OH})$; Octacalcium phosphate (OCP): $\mathrm{Ca}_{8} \mathrm{H}_{2}\left(\mathrm{PO}_{4}\right)_{6} \cdot 5 \mathrm{H}_{2} \mathrm{O}$; Calcite: $\mathrm{CaCO}_{3}$.

\begin{tabular}{lrrr}
\hline & BCS-1 & BCS-2 & c-SBF \\
\hline $\mathrm{p}\left(\mathrm{CO}_{2}\right)$ [atm. & $5.0 \%$ & $5.0 \%$ & $1.0 \%$ \\
$\mathrm{pH}$ (calculated) & 7.40 & 7.40 & $7.34^{a}$ \\
$\sigma_{\mathrm{HA}}$ & 15.23 & 14.15 & 12.84 \\
$\sigma_{\mathrm{OCP}}$ & 1.82 & 1.55 & 1.37 \\
$\sigma_{\text {calcite }}$ & 0.99 & 1.08 & -0.18 \\
\hline
\end{tabular}

${ }^{a}$ The calculation is based on the assumption of a closed system, where exchange of $\mathrm{CO}_{2}$ with the atmosphere is not allowed. During the actual preparation of $\mathrm{c}-\mathrm{SBF}, \mathrm{CO}_{2}$ loss from the solution could take place. In equilibrium with the $0.04 \% \mathrm{CO}_{2}$ in air, the calculated $\mathrm{pH}$ is 7.51 . 
Table 3. Statistical design of experiments

\begin{tabular}{ccccc}
\hline Factor & Definition & Levels & & 3 \\
\hline A & NaOH treatment & No & Yes & \\
B & Heat treatment & No & Yes & \\
C & SBF & BCS-1 & BCS-2 & c-SBF \\
D & BSA & No & Yes & \\
E & Replicate & 1 & 2 & \\
\hline
\end{tabular}

Table 4. Summary of HA deposition on four surfaces in different SBFs.

\begin{tabular}{|c|c|c|c|c|c|c|c|}
\hline \multirow{2}{*}{ Treatment } & \multirow{2}{*}{ Main crystalline phases } & BCS-1 & BCS-2 & $\mathrm{c}-\mathrm{SBF}$ & BCS-1 & BCS-2 & $\mathrm{c}-\mathrm{SBF}$ \\
\hline & & \multicolumn{3}{|c|}{ No BSA } & \multicolumn{3}{|c|}{$1 \mathrm{~g} / \mathrm{L} \mathrm{BSA}$} \\
\hline-- & $\mathrm{Ti}$ & - & - & - & - & - & - \\
\hline Heat & $\mathrm{Ti}, \mathrm{TiO}_{2}$ (rutile) & - & - & - & - & - & - \\
\hline $\mathrm{NaOH}$ & $\mathrm{Ti}, \mathrm{Na}_{0.8} \mathrm{H}_{1.2} \mathrm{Ti}_{3} \mathrm{O}_{7}$ & $\checkmark$ & $\checkmark$ & $\checkmark$ & $\checkmark$ & $\checkmark$ & - \\
\hline $\mathrm{NaOH}$, heat & $\mathrm{Ti}, \mathrm{TiO}_{2}$ (rutile), $\mathrm{Na}_{2} \mathrm{Ti}_{6} \mathrm{O}_{13}$ & $\checkmark$ & $\checkmark$ & - & $\checkmark$ & - & - \\
\hline
\end{tabular}

Table 5. Assignments of FTIR bands of $\mathrm{NaOH}$ treated Ti immersed in different SBFs.

\begin{tabular}{cccccc}
\hline $\begin{array}{c}\text { Wavenumber } \\
{\left[\mathrm{cm}^{-1}\right]}\end{array}$ & Component & HA (BCS-1) & HA (BCS-2) & HA (c-SBF) & HA (BCS-1+BSA) \\
\hline 1652 & BSA & & & & $\checkmark$ \\
1538 & $\mathrm{BSA}$ & & & & $\checkmark$ \\
1417 & $\left(\mathrm{CO}_{3}\right)^{2-}$ & $\checkmark$ & $\checkmark$ & $\checkmark$ & $\checkmark$ \\
1019 & $\left(\mathrm{PO}_{4}\right)^{3-}$ & $\checkmark$ & $\checkmark$ & $\checkmark$ & $\checkmark$ \\
872 & $\left(\mathrm{CO}_{3}\right)^{2-}$ & $\checkmark$ & $\checkmark$ & $\checkmark$ & $\checkmark$ \\
601 & $\left(\mathrm{PO}_{4}\right)^{3-}$ & $\checkmark$ & $\checkmark$ & $\checkmark$ & $\checkmark$ \\
557 & $\left(\mathrm{PO}_{4}\right)^{3-}$ & $\checkmark$ & $\checkmark$ & & $\checkmark$ \\
\hline
\end{tabular}

Table 6. Statistical design of experiments to investigate the effect of BSA concentrations.

\begin{tabular}{cccccc}
\hline Factor & Definition & Levels & & 3 & 4 \\
\hline A & Time delay (d) & 3 & 7 & 14 & 5 \\
B & BSA (g/L) & 0 & 0.1 & 1 & \\
C & Replicate & 1 & 2 & & \\
\hline
\end{tabular}




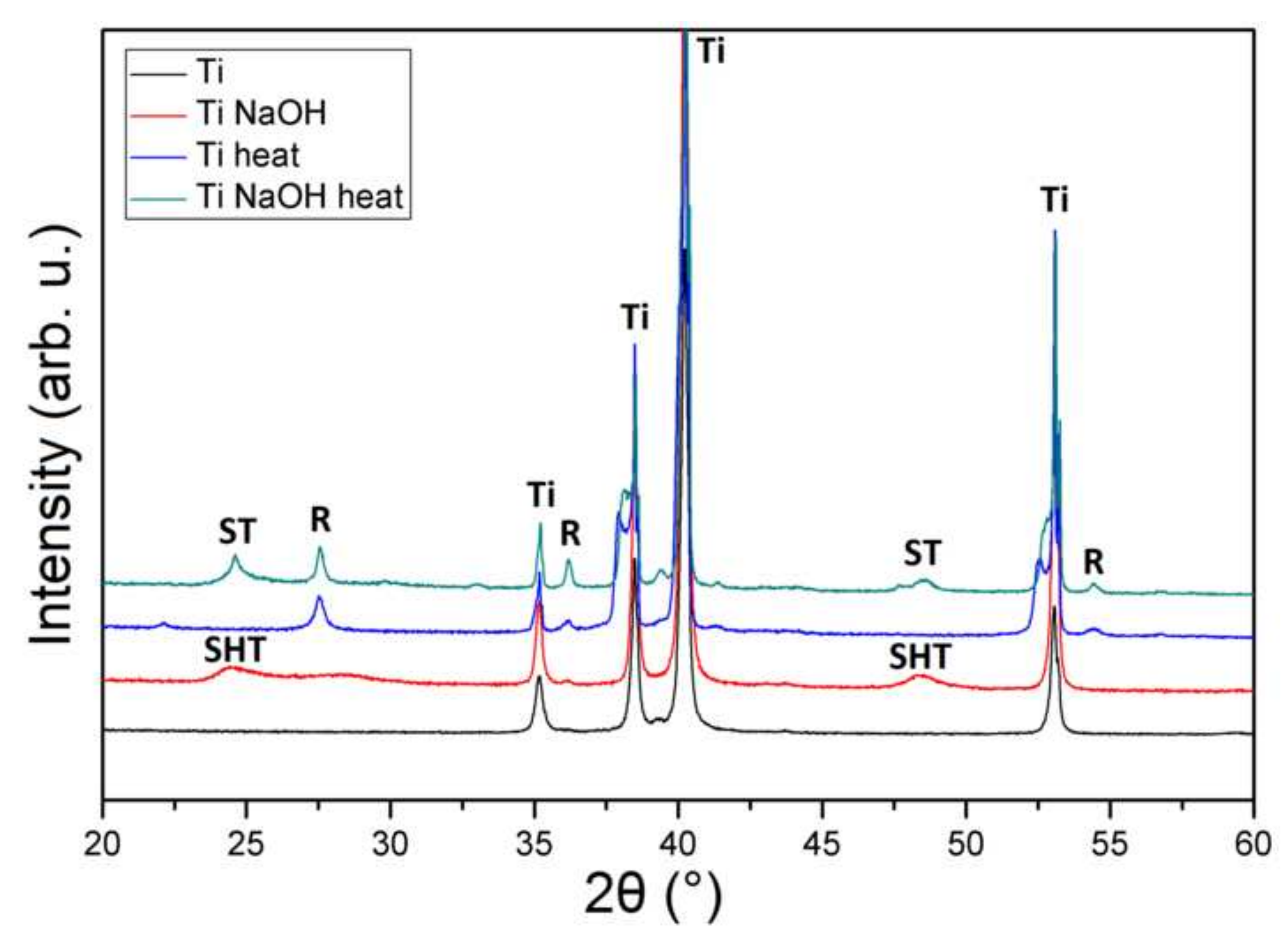




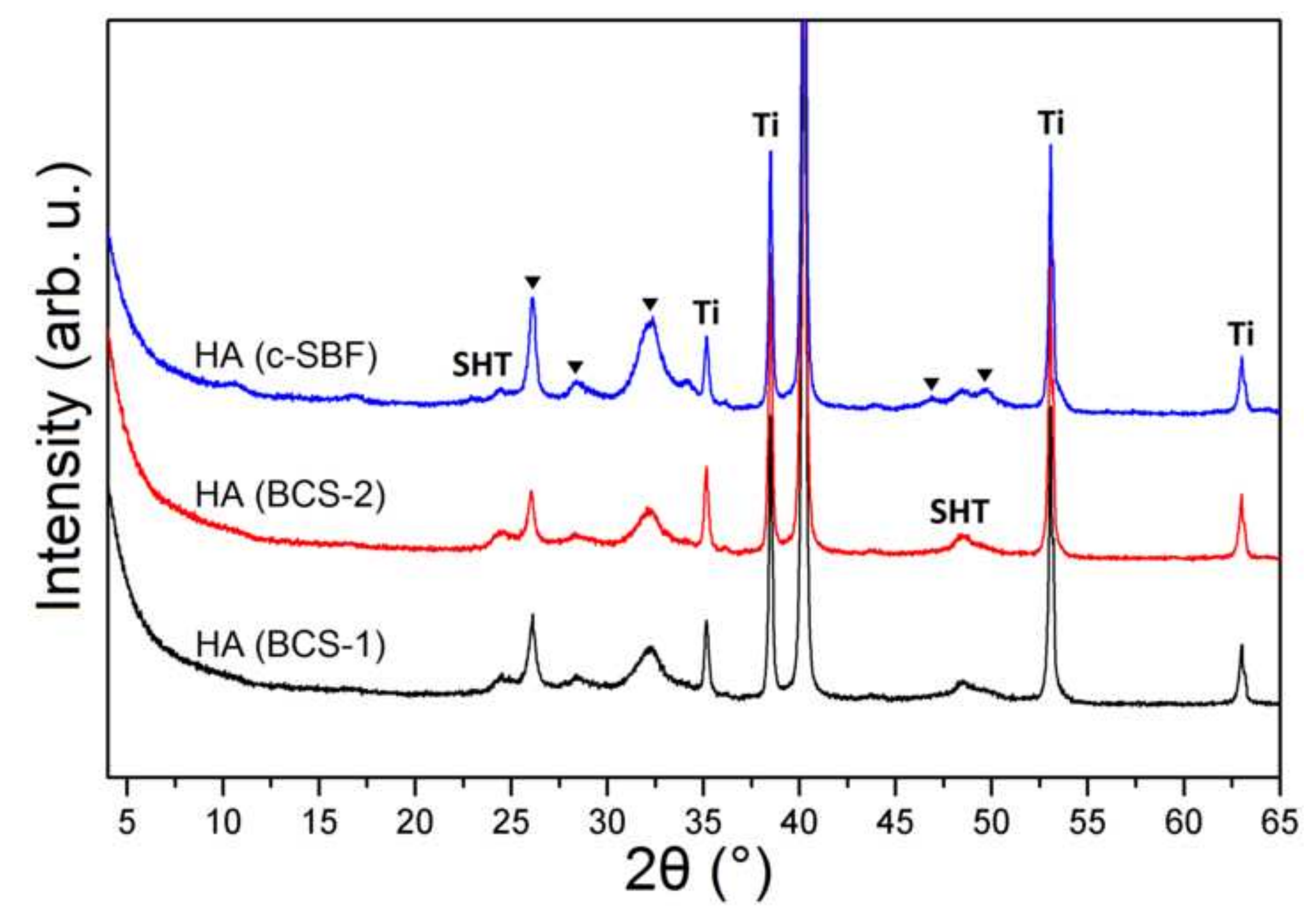




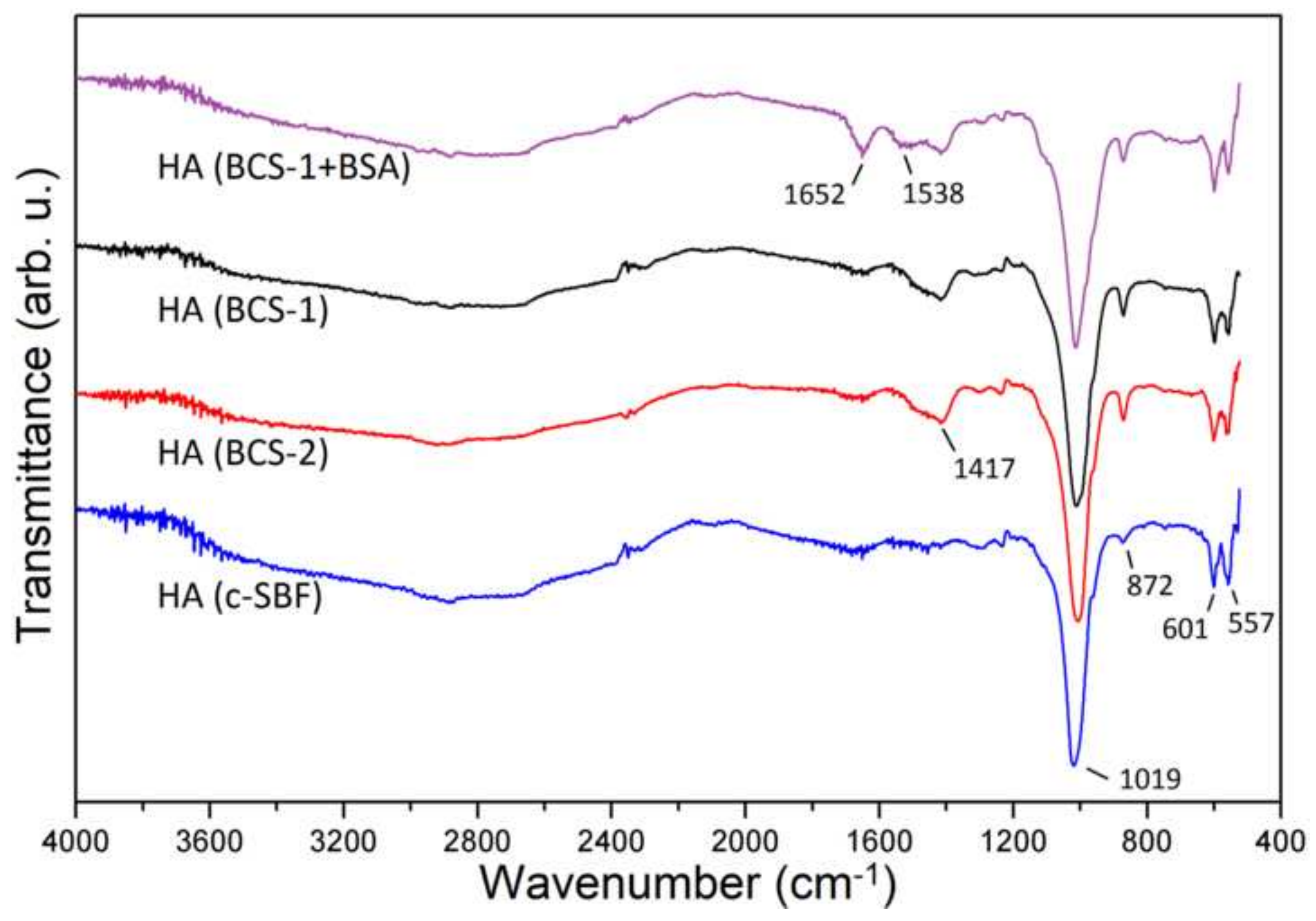




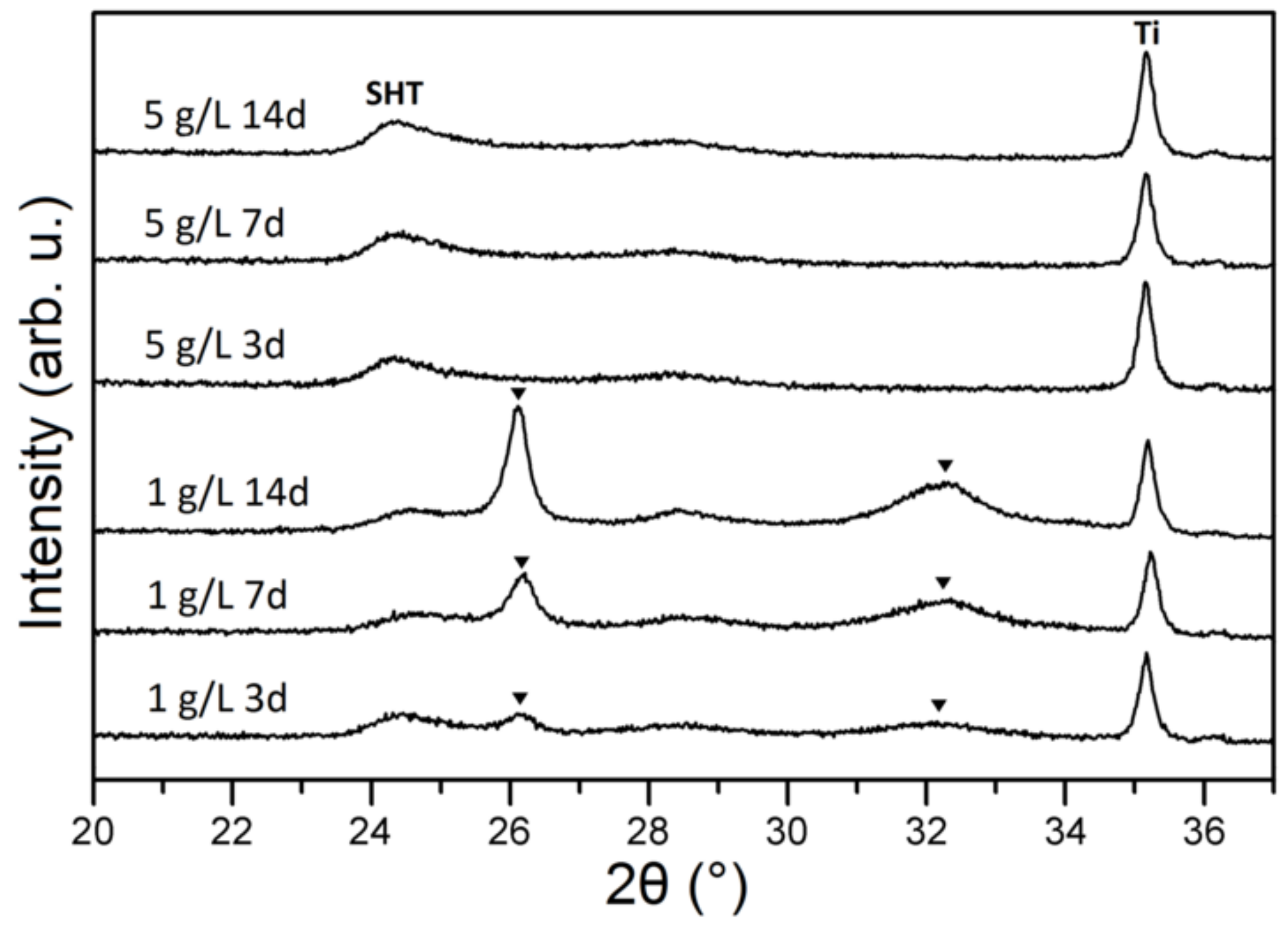




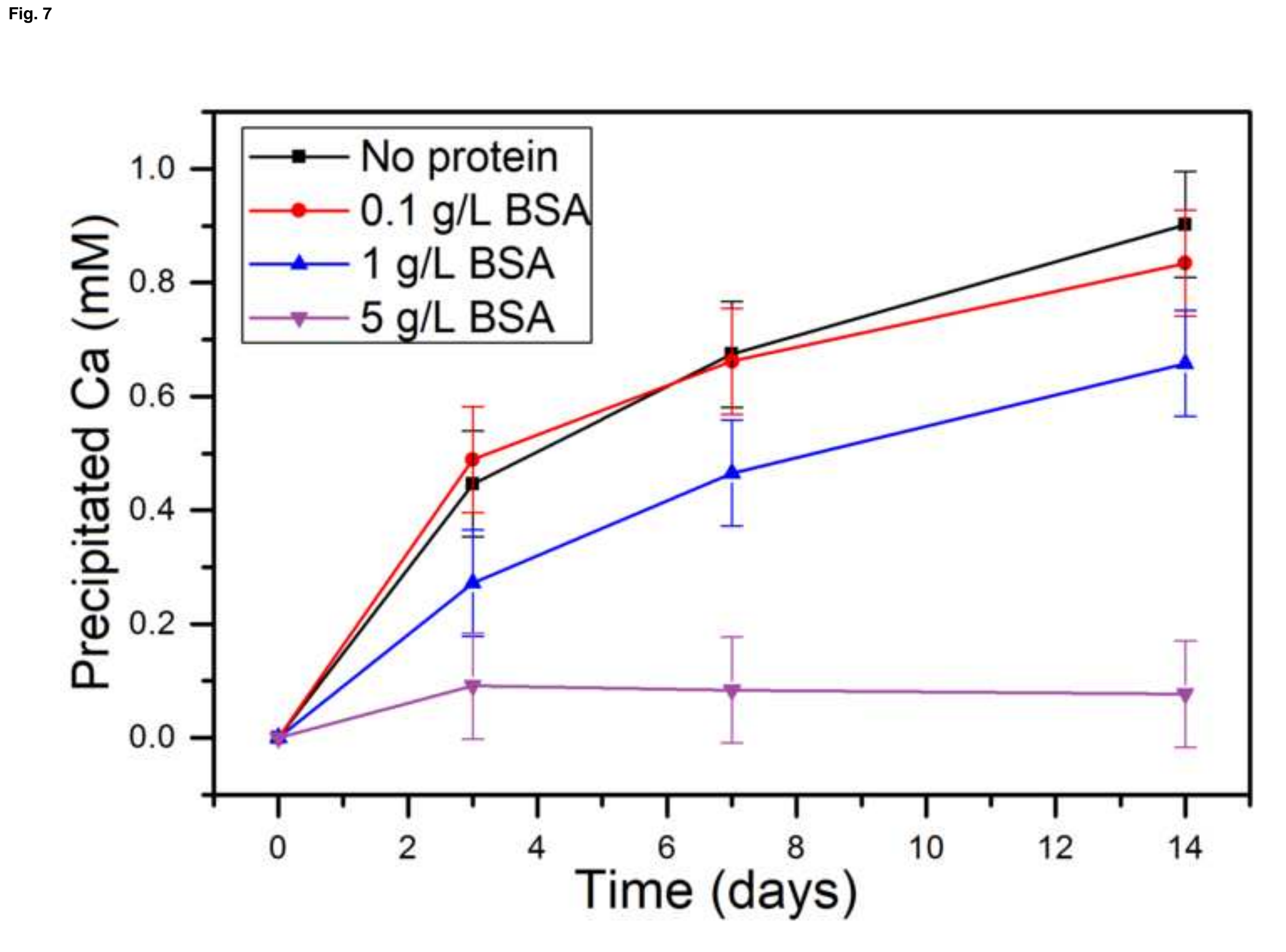

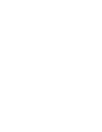

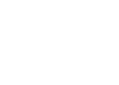

.

.
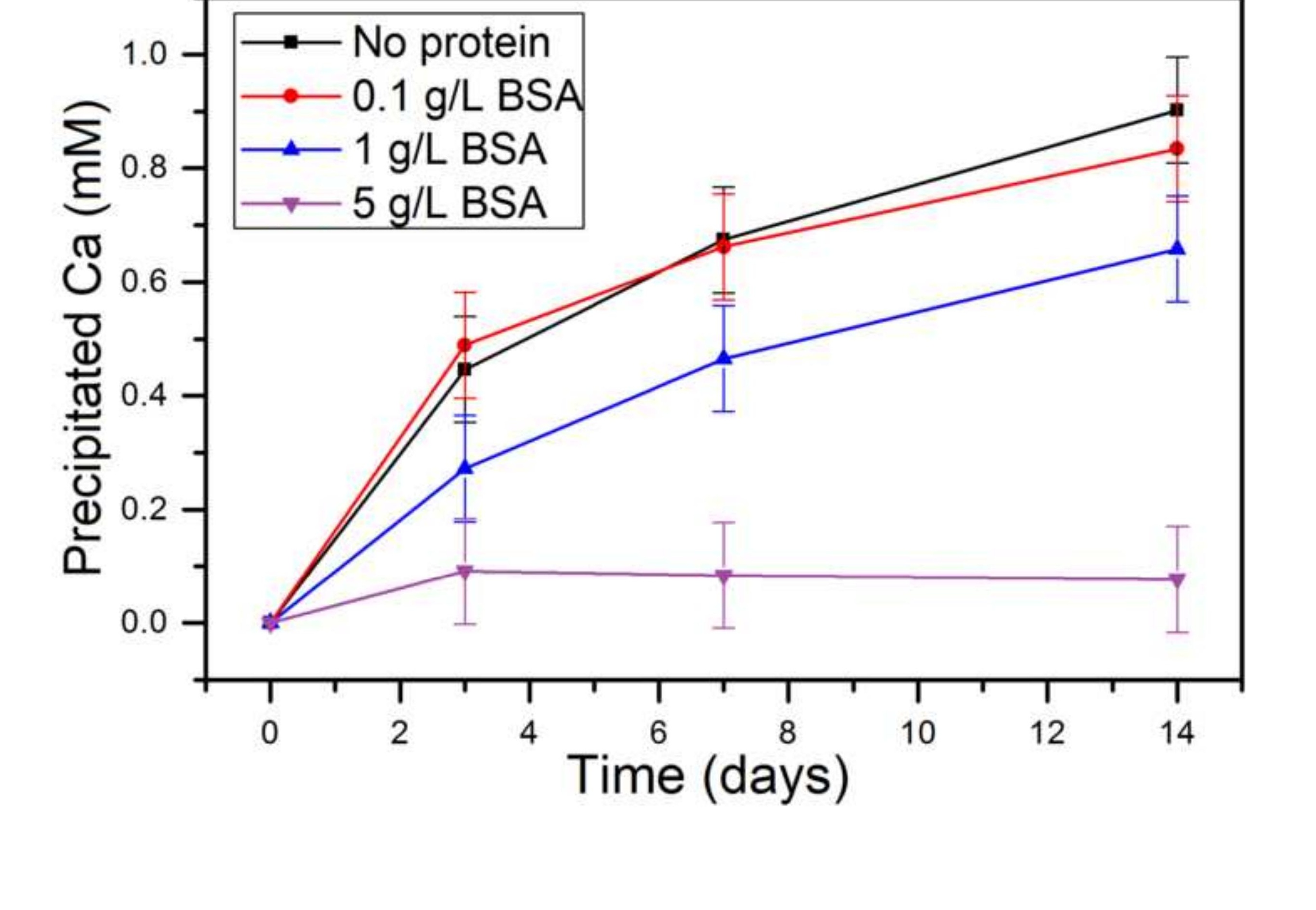


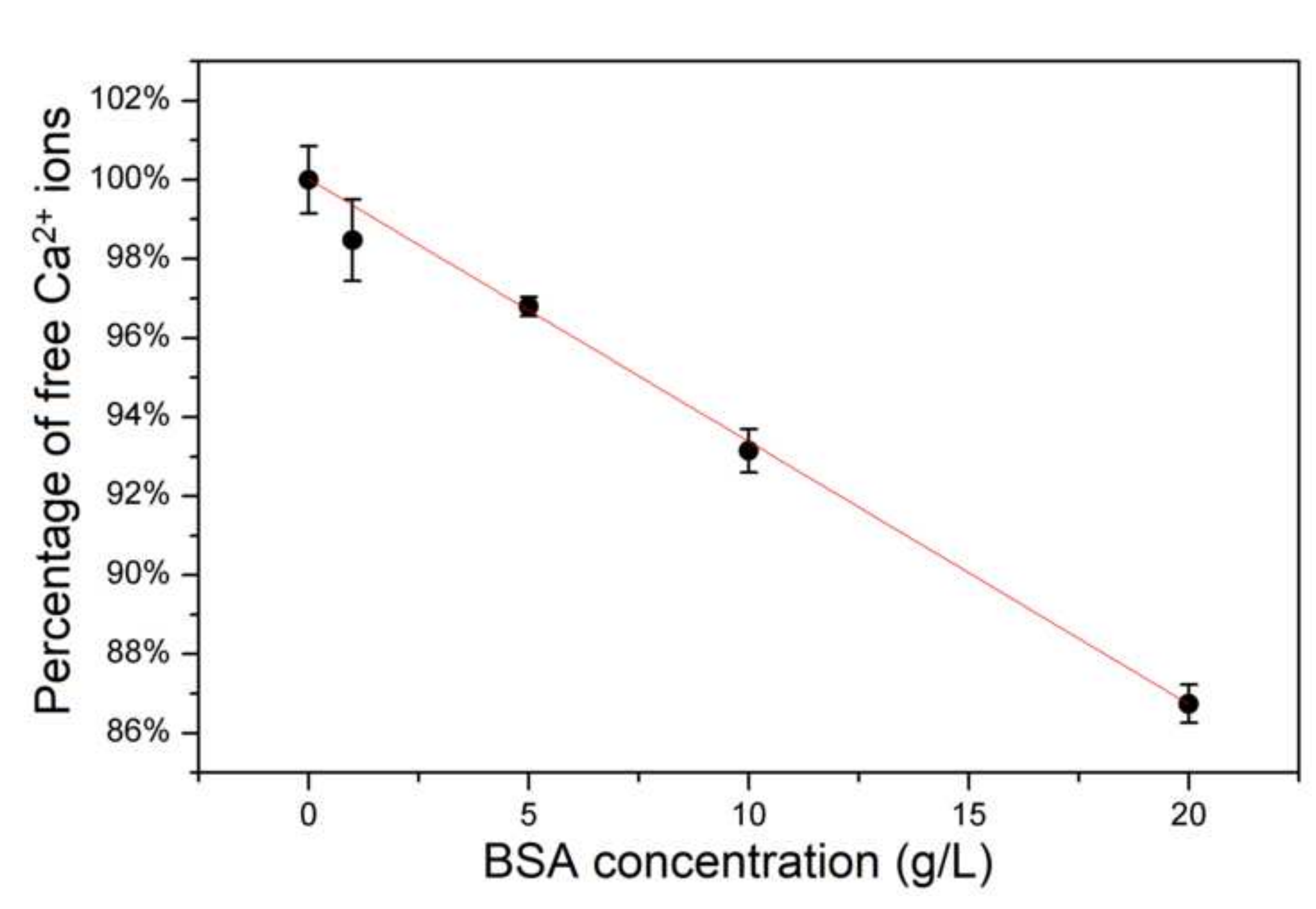

Fig. 8

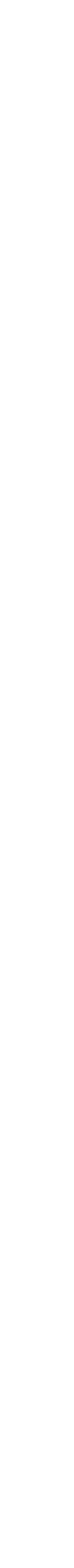




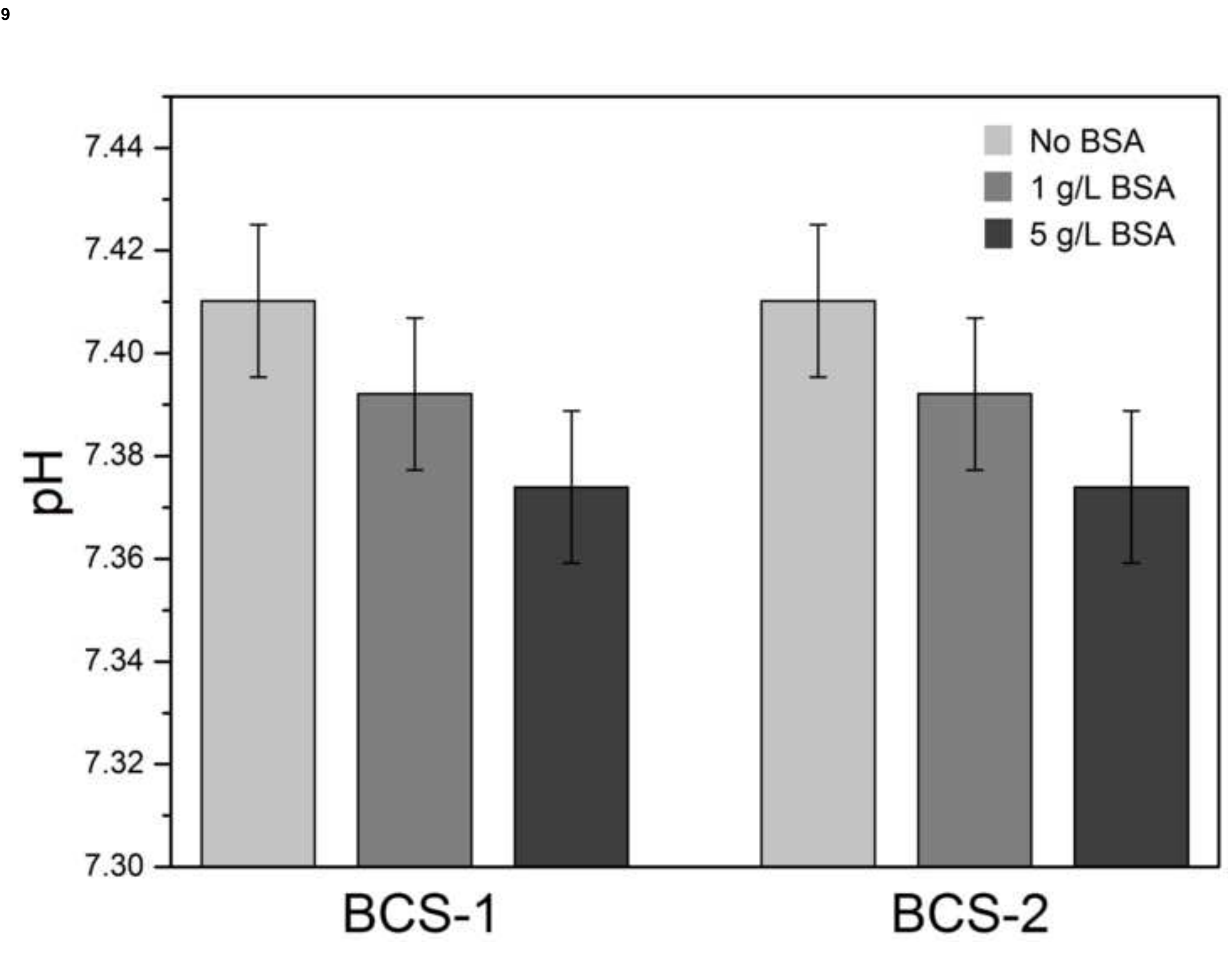
. 

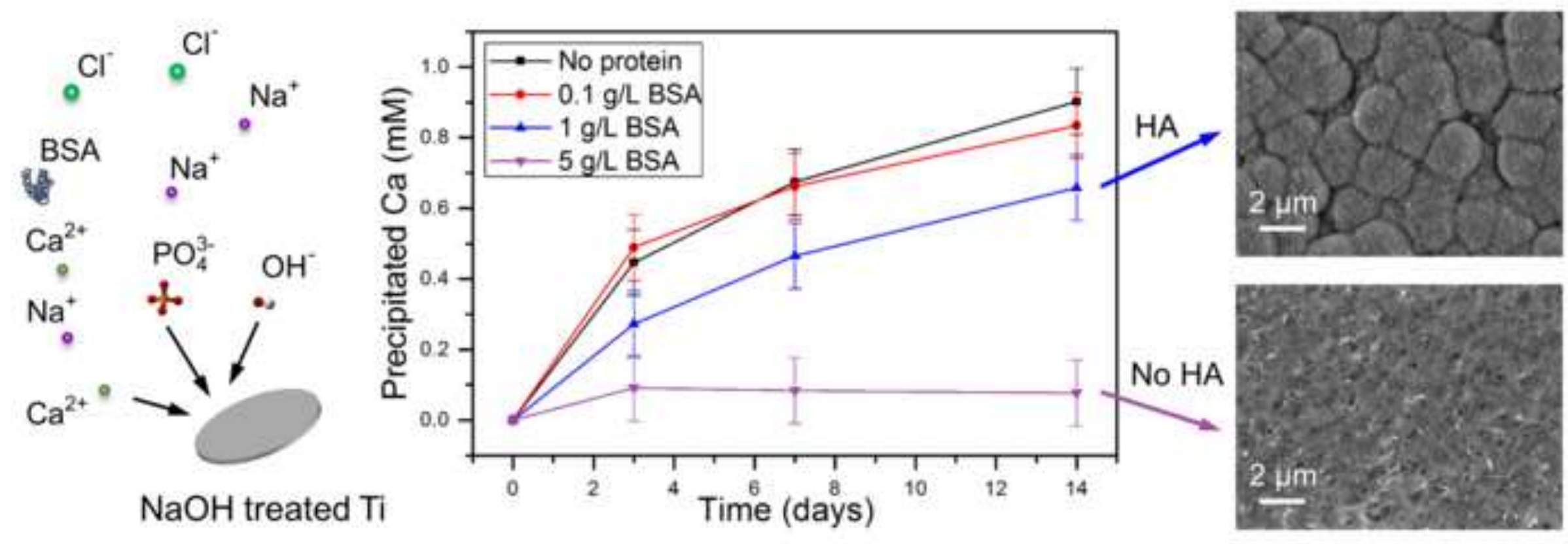

$\mathrm{NaOH}$ treated $\mathrm{Ti}$ 